\title{
PERANCANGAN DESAIN GRAFIS MEDIA PROMOSI WEBSITE PASAR PAPRINGAN BAGI KELUARGA URBAN DI INDONESIA
}

\author{
Steven Arden, R.A. Dita Saraswati, Puspita Yuli Pradita \\ (Email: stevenarden1464074@yahoo.com ) \\ Desain Komunikasi Visual \\ Fakultas Seni Rupa dan Desain \\ Universitas Kristen Maranatha \\ Jl. Prof.drg. Suria Sumantri, MPH no. 65, Bandung, Indonesia
}

\begin{abstract}
ABSTRAK
Pasar Papringan terletak di Dusun Ngadiprono, Desa Ngadimulyo, Kecamatan Kedu, Temanggung, Jawa Tengah. Pasar Papringan mempunyai gagasan besar untuk membangun desa dari desa dengan cara merevitalisasinya. Pasar Papringan memiliki potensi yang bagus untuk daerah wisata sekaligus edukasi dengan konsep kembali ke alam, sayangnya belum ada media promosi yang representatif untuk memperkenalkan tempat wisata ini pada masyarakat urban. Pedagang yang berjualan di sana juga menggunakan bahan-bahan yang ramah lingkungan dan sehat. Hal inilah yang membuat Pasar Papringan berpotensi untuk dipromosikan agar lebih dikenal oleh keluarga urban di Indonesia. Metode penelitian yang digunakan yaitu observasi lapangan, wawancara terhadap aktivis Pasar Papringan, dan mencari target market dengan metode kuantitatif melalui kuesioner online terhadap 100 responden. Konsep kreatif yang diangkat dalam desain media promosi Pasar Papringan adalah tradisional, unik, dan memperlihatkan kegiatan khas pada daerah tersebut yang tidak dimiliki oleh pasar tradisional lainnya. Media utama yang digunakan sebagai media promosi adalah website karena sifatnya interaktif, menarik, memiliki jangkauan global, dan informasinya yang up to date. Hasil dari perancangan promosi menggunakan website diharapkan akan menciptakan peluang bagi Pasar Papringan untuk lebih banyak dilihat warga di kota-kota besar lainnya dan mampu menjangkau kaum urban di kota lain yang juga sebagai pegiat wisata tradisional.
\end{abstract}

Kata Kunci: keluarga urban; media promosi; Pasar Papringan; Temanggung; website

\begin{abstract}
Papringan Market is located in Ngadiprono Hamlet, Ngadimulyo Village, Kedu District, Temanggung, and Central Java. The Papringan market has a big idea to build a village from the village by revitalizing it. The Papringan market has good potential for tourist areas, because it has a unique transaction method, this market uses "pring" coins for trading. In addition, the creation of this market also changes the public order from the unused or the disposal of wasteland into a useful land. The design goal is to promote the Papringan Market to be better known by urban families in Indonesia.The research method used is Field observation, interviews with Papringan Market activists, and target markets research with quantitative methods through online questionnaires on 100 respondents. The main media used are Website and Video. The visuals raised the traditional elements such as bamboo, unique elements of space, and typical activities in the area that are not owned by other traditional markets. This promotion uses websites as the main media, because it is interactive, attractive, global reach, and up-to-date information. The results of this design are expected the Papringan Market opportunity more visible to residents in other big cities and able to reach urbanites in other cities, which are in fact traditional tourism activists.
\end{abstract}

Keywords: Papringan Market; promotion Media; Temanggung; urban family; website 
Serat Rupa Journal of Design, July 2019, Vol.3, No.2: 93-111

E-ISSN: 2477-586X, ISSN: 2338-3348 | https://doi.org/10.28932/srjd.v3i2.1160 | Received: 07-01-2018, Accepted: 25-07-2019

Steven Arden, R.A. Dita Saraswati, Puspita Yuli Pradita

Perancangan Desain Grafis Media Promosi Website Pasar Papringan Bagi Keluarga Urban di Indonesia

\section{PENDAHULUAN}

Pasar Papringan terletak di Dusun Ngadiprono, Desa Ngadimulyo, Kecamatan Kedu, Temanggung, Jawa Tengah. Papringan dalam Bahasa Jawa mempunyai arti rumpun bambu. Pasar Papringan mempunyai gagasan besar untuk membangun desa dari desa dengan merevitalisasinya. Warga diajak untuk tinggal dan berkarya di desa supaya mereka dapat menciptakan lapangan kerja yang memadai dan menyelesaikan permasalahanpermasalahan di desa. Hal ini terjadi karena banyak anak muda desa yang bekerja di kota atau pindah ke kota karena di desa tidak ada pekerjaan yang layak. Salah satu tujuan pasar ini adalah untuk meningkatkan kualitas produk desa sehingga warga desa memiliki kebanggaan akan desanya. Penggagas Pasar Papringan adalah Spedagi, sebuah lembaga masyarakat yang bergerak di bidang revitalisasi desa, yang memikirkan tentang konservasi lingkungan alam dengan pendekatan kreatif. Spedagi yang mendampingi sebuah komunitas desa bernama Komunitas Mata Air, berhasil mengubah wajah sebuah kebun bambu yang semula merupakan tempat pembuangan atau timbunan sampah desa diubah menjadi lahan yang memiliki nilai lebih, dan juga mengangkat perekonomian masyarakat desa. Tempat tersebut menjadi lebih nyaman serta menjadi tempat konservasi bambu sekaligus tempat wisata yang edukatif.

Pasar ini mempunyai konsep 'kembali ke alam' karena para pedagang di Pasar Papringan tidak memakai kemasan plastik dan menggantinya dengan besek (wadah bambu). Salah satu produk yang dijual di Pasar Papringan adalah makanan tradisional yang mulai langka. Kuliner di Pasar Papringan merupakan kuliner tanpa penyedap rasa MSG (monosodium glutamate), tanpa pengawet, pewarna buatan, maupun pemanis buatan. Singkatnya, pedagang menggunakan bahan-bahan yang ramah lingkungan dan sehat. Produk kerajinan yang dijual di sana merupakan produk buatan warga desa dengan kualitas baik, di antaranya mainan anak-anak, topi, dan keranjang bambu. Keunikan lain dari pasar ini adalah sistem transaksinya yang bertransaksi bukan menggunakan mata uang Rupiah, namun menggunakan mata uang buatan lokal yaitu 'koin pring', kepingan uang yang terbuat dari bambu. Kebun bambu yang semula kumuh telah bertransformasi menjadi pasar yang menarik, unik, dan berdaya tarik nasional bahkan internasional. Pasar Papringan menjadi contoh bahwa desa pun dapat menjual produk-produk berkualitas secara mandiri dengan identitas desa yang kuat. 
Serat Rupa Journal of Design, July 2019, Vol.3, No.2: 93-111

E-ISSN: 2477-586X, ISSN: 2338-3348 | https://doi.org/10.28932/srjd.v3i2.1160| Received: 07-01-2018, Accepted: 25-07-2019

Steven Arden, R.A. Dita Saraswati, Puspita Yuli Pradita

Perancangan Desain Grafis Media Promosi Website Pasar Papringan Bagi Keluarga Urban di Indonesia

Pasar ini sangat cocok sebagai salah satu lokasi berkunjung wisata keluarga karena ada banyak unsur edukasi di dalamnya. Pasar Papringan memiliki potensi yang bagus untuk daerah wisata, namun sayangnya belum ada media promosi yang representatif untuk memperkenalkan tempat wisata ini pada masyarakat urban. Pasar ini hanya buka setiap Minggu Wage dan Pon, hal tersebut juga lah yang membuat pasar ini belum banyak dikenal warga di daerah lingkungannya sendiri apalagi di luar kota. Tujuan dari penelitian ini adalah merancang promosi Pasar Papringan agar lebih banyak wisatawan yang datang berkunjung. Selain itu, diharapkan waktu pasar dibuka atau diadakan dapat ditambah harinya sehingga masyarakat sekitar yang ingin berjualan bertambah dan dapat membantu meningkatkan perekonomian mereka.

\section{METODE PENELITIAN}

Metode penelitian yang digunakan adalah metode kualitatif berupa observasi lapangan, proses wawancara tenaga ahli dengan detail sebagai berikut:

1. Observasi langsung di Dusun Ngadiprono, Desa Ngadimulyo, Kecamatan Kedu, Temanggung, Jawa Tengah.

2. Wawancara dengan narasumber yaitu Fransisca Callista selaku Project Manager Pasar Papringan Ngadiprono, Temanggung dan wawancara terhadap masyarakat sekitar Pasar Papringan.

3. Kuesioner online disebarkan ke 100 responden yang tinggal di kota-kota besar di Indonesia.

4. Studi literatur dari buku dan website terpercaya tentang teori promosi, teori tipografi yang digunakan dalam mempromosikan Pasar Papringan.

5. Dokumentasi visual berupa perekaman data visual secara fotografi dan videografi.

Adapun teori yang digunakan untuk mendukung data yang dibutuhkan dalam penelitian tentang perancangan promosi Pasar Papringan antara lain:

Promosi adalah segala bentuk komunikasi yang digunakan untuk menginformasikan (to inform), membujuk (to persuade), atau mengingatkan orang-orang tentang produk yang dihasilkan organisasi, individu ataupun rumah tangga (Simamora, 2003). 
Serat Rupa Journal of Design, July 2019, Vol.3, No.2: 93-111

E-ISSN: 2477-586X, ISSN: 2338-3348 | https://doi.org/10.28932/srjd.v3i2.1160 | Received: 07-01-2018, Accepted: 25-07-2019

Steven Arden, R.A. Dita Saraswati, Puspita Yuli Pradita

Perancangan Desain Grafis Media Promosi Website Pasar Papringan Bagi Keluarga Urban di Indonesia

Menurut Henry Simamora (2011) ada beberapa alasan para pemasar melakukan promosi yaitu:

a. Menyediakan informasi

Pembeli dan penjual mendapat manfaat dari fungsi informasi yang sanggup dilakukan oleh promosi. Para pembeli menemukan program baru yang dapat membantunya dan para penjual dapat menginformasikan kepada calon pelanggan tentang barang dan jasa.

b. Merangsang permintaan

Para pemasar menginginkan konsumen membeli produknya dan mereka menggunakan promosi untuk membuat konsumen melakukan permintaan.

c. Membedakan produk

Organisasi-organisasi mencoba membedakan mereka dan produknya melalui penggunaan promosi, khususnya produk yang tidak banyak berbeda dari para pesaingnya.

d. Mengingat para pelanggan saat ini mengingatkan para pelanggan akan manfaat dari produk perusahaan bisa mencegah mereka berpaling kepada pesaing pada saat mereka memutuskan untuk mengganti atau memutakhirkan produknya.

e. Menghadang pesaing promosi dapat digunakan untuk menghadapi upaya pemasaran dari pesaing untuk melawan kampanye periklanannya.

f. Menjawab berita negatif kadangkala kompetisi bukanlah penjualan produk serupa dan perusahaan lainnya. Seringkali perusahaan menjadi korban publisitas dan pemalsuan.

g. Memuluskan fluktuasi-fluktuasi permintaan. Perusahaan banyak mengalami tantangan-tantangan permintaan musiman, para pelanggan membeli lebih banyak selama beberapa bulan tertentu dan berkurang pada bulan-bulan lainnya.

\section{Media Promosi}

Promosi memiliki medium-medium dalam aktivitasnya yang disebut media promosi. Media promosi memiliki peranan yang cukup besar dalam penjualan sebuah barang atau jasa. Media promosi merupakan sarana yang digunakan untuk mengantarkan, menyebarluaskan informasi terkait barang dan jasa kepada target pasar. Menurut Russel dan Lane (1992: 213) dalam komunikasi, penggunaan medium merupakan alat perantara yang digunakan untuk menyampaikan pesan dari komunikator kepada komunika. Menurut (Kasali, 1992) dalam periklanan media promosi dikelompokkan menjadi 2, yaitu : 
Serat Rupa Journal of Design, July 2019, Vol.3, No.2: 93-111

E-ISSN: 2477-586X, ISSN: 2338-3348 | https://doi.org/10.28932/srjd.v3i2.1160| Received: 07-01-2018, Accepted: 25-07-2019

Steven Arden, R.A. Dita Saraswati, Puspita Yuli Pradita

Perancangan Desain Grafis Media Promosi Website Pasar Papringan Bagi Keluarga Urban di Indonesia

\section{Media Lini Atas (Above the Line)}

Media lini atas adalah media yang tidak langsung mengenai audiens dan merupakan media yang menggunakan media masa dalam pemasaran barang atau jasa. Media lini atas digunakan untuk menjelaskan sebuah konsep atau ide dengan target audiens yang luas. Media yang digunakan seperti televisi, radio, media cetak, internet, dan sebagainya.

\section{Media Lini Bawah (Below the Line)}

Media lini bawah adalah media yang bertujuan merangkul konsumen dengan cara berinteraksi langsung dengan audiens dan target audiens yang terbatas. Media yang digunakan seperti souvenir, event, program-program, dan sebagainya.

\section{Media Through The Line}

Selain itu, menurut Maulana. E Amalia (2008) ada media lini ketiga, yakni yang disebut Istilah Through the Line yakni media untuk menjembatani antara pihak perusahaan jasa komunikasi periklanan yang ingin membuat gambaran konkret periklanan yang ingin membuat gambaran terhadap segmen jasa kreatif komunikasi yang ditawarkannya. Media Through the Line adalah media promosi yang mengandung keduanya yaitu Above the Line yang mengandung Below the Line, dan sebaliknya Below the Line yang mengandung Above the Line. Contohnya pameran produk dengan pembagian brosur dan katalog yang menyertakan alamat website toko online, dan event di outlet tertentu yang disebarluaskan lewat iklan radio atau media sosial.

Website banyak diperlukan untuk berbagai kepentingan berkaitan dengan penyampaian informasi mulai dari perusahaan besar, perusahaan kecil, lembaga pemerintahan, pendidikan, dunia hiburan, dan masih banyak lagi. Website merupakan sarana yang efektif untuk melakukan promosi produk dan jasa sehingga cukup banyak perusahaan penjualan barang dan jasa yang membuat website atau dapat disebut dengan e-commerce. Website juga menjadi menjadi informasi yang diminati selain media informasi lainnya. Hal ini disebabkan karena sifat website yang interaktif, menarik, jangkauan global dan informasinya yang up to date (Arwiedya, 2011).

\section{PEMBAHASAN}

Pasar Papringan didirikan akhir tahun 2015 oleh Spedagi, sebuah lembaga masyarakat yang bergerak di bidang revitalisasi desa, yang memikirkan tentang konservasi lingkungan alam dengan pendekatan kreatif. Spedagi yang mendampingi sebuah komunitas desa 
Serat Rupa Journal of Design, July 2019, Vol.3, No.2: 93-111

E-ISSN: 2477-586X, ISSN: 2338-3348 | https://doi.org/10.28932/srjd.v3i2.1160 | Received: 07-01-2018, Accepted: 25-07-2019

Steven Arden, R.A. Dita Saraswati, Puspita Yuli Pradita

Perancangan Desain Grafis Media Promosi Website Pasar Papringan Bagi Keluarga Urban di Indonesia

bernama Komunitas Mata Air berhasil mengubah wajah sebuah kebun bambu yang semula merupakan tempat pembuangan atau timbunan sampah desa diubah menjadi lahan yang memiliki nilai lebih, dan juga mengangkat perekonomian masyarakat desa.

Promosi Pasar Papringan menggunakan media utama website sebagai media penyampaian informasinya kepada target audiensnya. Website dikategorikan sebagai media Through The Line karena merupakan media Below The Line Digital yang melakukan aktivitas Media Above The Line seperti mempromosikan brosur online dan juga berita video online. Menurut Asep Herman Suyanto (2008), website dapat diartikan sebagai kumpulan halaman yang menampilkan informasi data teks, data gambar diam atau bergerak, data animasi, suara, video atau gabungan dari semuanya, baik yang bersifat statis maupun dinamis yang membentuk satu rangkaian bangunan yang saling terkait dengan masing-masing dihubungkan dengan jaringan-jaringan halaman (hyperlink). Bersifat statis apabila isi informasi website tetap, jarang berubah, dan isi informasinya searah hanya dari pemilik website. Bersifat dinamis apabila isi informasi website selalu berubah-ubah dan isi informasinya interaktif dua arah berasal dari pemilik serta pengguna website.

Untuk mempromosikan daerah tersebut, perlu diangkat keunikan yang dimiliki Pasar Papringan dan menjadikannya sebagai fokus objek wisata dengan konsep kembali ke alam. Keunikannya antara lain sebagai berikut :

1. Koin pring sebagai alat transaksi

Kegiatan berjual beli di Pasar Papringan tidak bisa memakai uang Rupiah sebagai alat pembayaran. Pembeli dan penjual harus menukarkan uang Rupiah itu dengan alat pembayaran yang oleh warga desa setempat disebut 'koin pring'. Bentuknya memang mirip koin, namun terbuat dari kayu dan bamboo berbentuk persegi panjang.

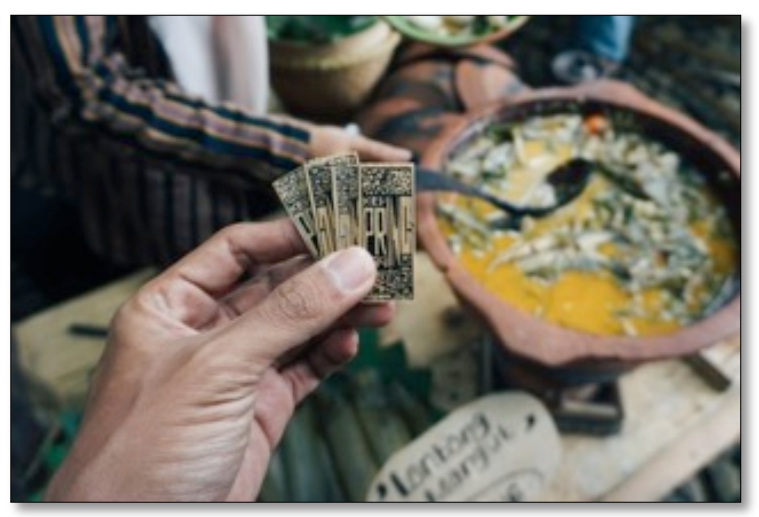

Gambar 1. Koin Pring, alat transaksi jual beli (Sumber: Spedagi, 2017) 
Serat Rupa Journal of Design, July 2019, Vol.3, No.2: 93-111

E-ISSN: 2477-586X, ISSN: 2338-3348 | https://doi.org/10.28932/srjd.v3i2.1160| Received: 07-01-2018, Accepted: 25-07-2019 Steven Arden, R.A. Dita Saraswati, Puspita Yuli Pradita

Perancangan Desain Grafis Media Promosi Website Pasar Papringan Bagi Keluarga Urban di Indonesia

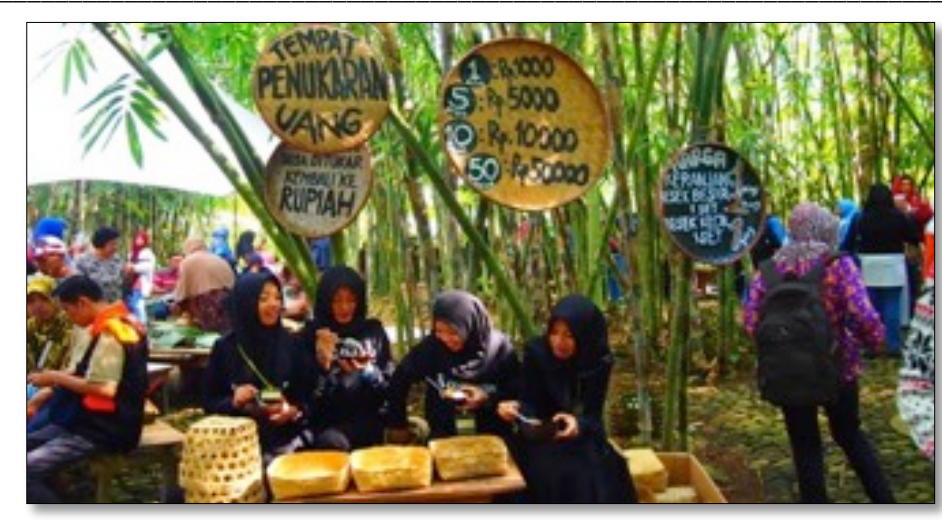

Gambar 2. Tempat penukaran koin pring (Sumber: Spedagi, 2017)

\section{Produk-produk tradisional yang khas}

Pasar Papringan menjual makanan tradisional, minuman, dan produk-produk kerajinan dari bambu. Makanan-makanan yang dijual memiliki nama unik dan beberapa di antaranya sudah jarang ditemui di pasar lain. Misalnya, samiler (kerupuk singkong), manggleng (olahan singkong), glanggem, rondo royal, sega megono, kacamata (olahan singkong dan parutan kelapa), ketan lupis, dan lainnya. Sementara minuman yang dijual mulai kelapa muda, adon-adon coro (jamu), dan masih banyak lainnya. Sedangkan produk kerajinan yang bisa dibeli di Pasar Papringan itu di antaranya topi dari bambu yang bentuknya mirip 'ekrak' namun ukuran kecil, radio dilapisi bahan kayu, dan bahkan ada sepeda yang sebagian kerangka terbuat dari bahan bambu.

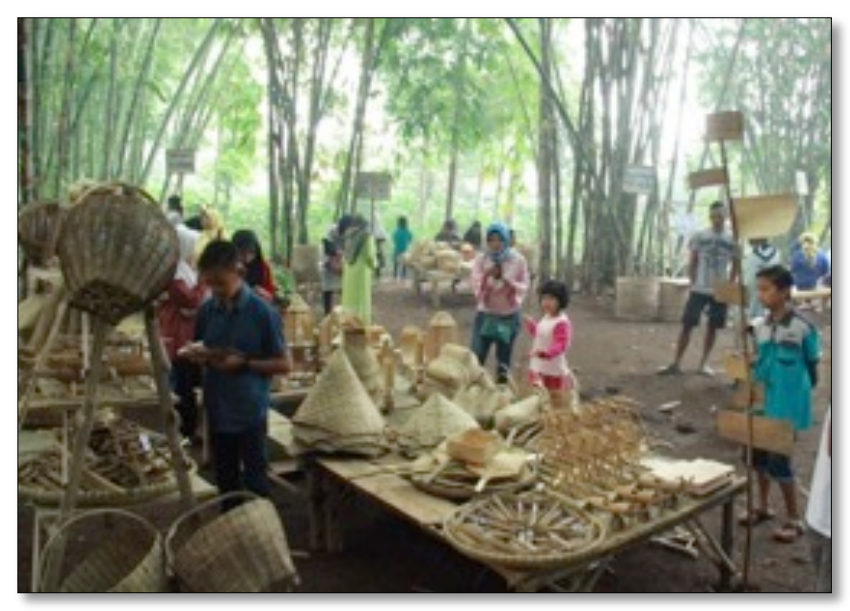

Gambar 3. Mainan dan kerajinan tradisional Pasar Papringan (Sumber: Spedagi, 2017)

3. Gerakan revitalisasi desa Spedagi 
Serat Rupa Journal of Design, July 2019, Vol.3, No.2: 93-111

E-ISSN: 2477-586X, ISSN: 2338-3348 | https://doi.org/10.28932/srjd.v3i2.1160 | Received: 07-01-2018, Accepted: 25-07-2019

Steven Arden, R.A. Dita Saraswati, Puspita Yuli Pradita

Perancangan Desain Grafis Media Promosi Website Pasar Papringan Bagi Keluarga Urban di Indonesia

Sebuah gerakan yang bertujuan membawa desa kembali ke harkat dasarnya sebagai komunitas lestari dan mandiri.

4. Revitalisasi lahan waste land atau pembuangan sampah.

Merefungsikan sebuah lahan yang awalnya hanya dijadikan tempat pembuangan sampah oleh warga desa menjadi sebuah lahan yang memiliki daya ekonomi dan daya tarik wisata

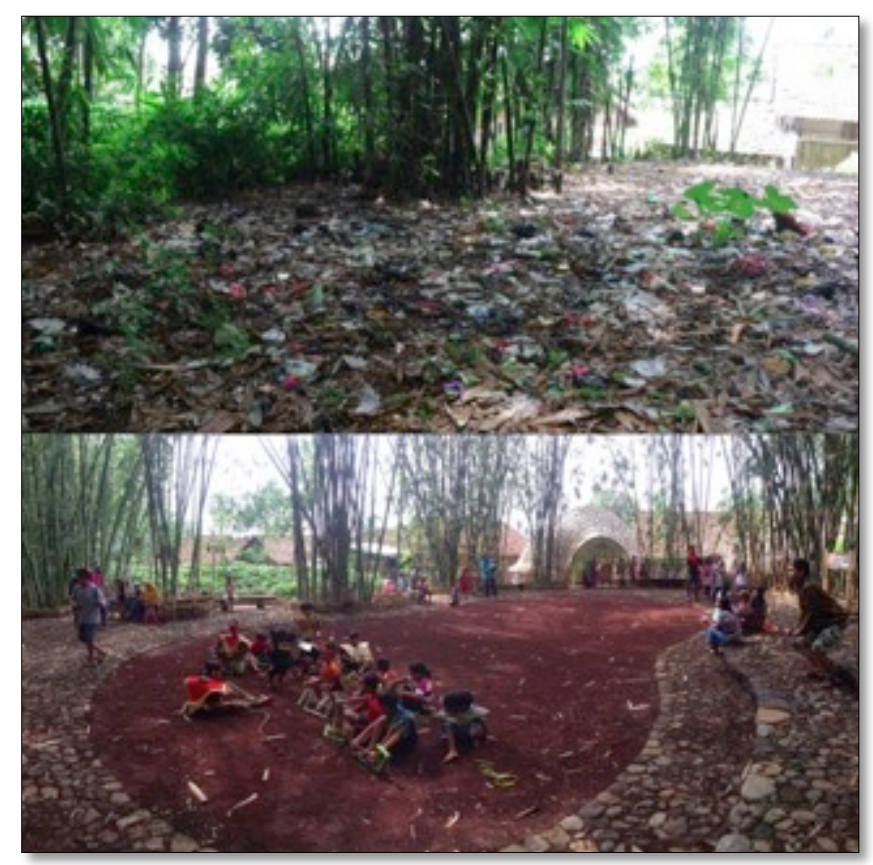

Gambar 4. Lahan kebun bambu sebelum dan sesudah Pasar Papringan (Sumber: Spedagi, 2017)

Langkah kedua untuk merancang desain media promosi Pasar Papringan adalah dengan melakukan analisis STP (segmenting, targeting, dan positioning), hasil yang didapat adalah sebagai berikut:

\section{a) Segmenting}

Segmen promosi ini adalah masyarakat kota-kota besar di Indonesia seperti: Jakarta, Bandung, Surabaya, Bali, Semarang, dan sebagainya, khususnya keluarga, semua usia, perempuan dan laki-laki dengan pendidikan SMA, S1, S2, dengan status ekonomi menengah, senang dengan suasana alam yang ditawarkan Pasar Papringan dan makan maupun minuman tradisional.

\section{b) Targeting}

Promosi ini ditujukan bagi keluarga urban, dengan status ekonomi menengah. Semua profesi dan bagi mereka yang senang dengan suasana alam dan nuansa tradisional yang menjadi keunikan dari Pasar Papringan.

c) Positioning 
Serat Rupa Journal of Design, July 2019, Vol.3, No.2: 93-111

E-ISSN: 2477-586X, ISSN: 2338-3348 | https://doi.org/10.28932/srjd.v3i2.1160| Received: 07-01-2018, Accepted: 25-07-2019

Steven Arden, R.A. Dita Saraswati, Puspita Yuli Pradita

Perancangan Desain Grafis Media Promosi Website Pasar Papringan Bagi Keluarga Urban di Indonesia

Positioning dalam perancangan promosi ini adalah Pasar Papringan yang dipromosikan bagi masyarakat urban dengan menawarkan konsep kembali ke alam.

Langkah selanjutnya, setelah mengetahui keunikan dari Pasar Papringan dan STP promosi yang akan dilakukan, maka konsep kreatif yang diangkat dalam desain media promosi Pasar Papringan adalah tradisional dengan memperlihatkan kegiatan khas pada daerah tersebut yang tidak dimiliki oleh pasar tradisional lainnya.

Dalam merancang promosi Pasar Papringan, konsep kreatif yang terbagi dalam konsep verbal dan konsep visual adalah sebagai berikut:

\section{Konsep Verbal}

Menggunakan bahasa Indonesia sebagai bahasa utamanya yang disisipi bahasa Jawa untuk menandakan ciri khas lokasi wilayah Pasar Papringan yang berada di Temanggung.

\section{Konsep Visual}

Konsep visual yang diangkat dalam desain media promosi Pasar Papringan adalah tradisional dengan memperlihatkan kegiatan khas pada daerah tersebut yang tidak dimiliki oleh pasar tradisional lainnya. Media utama dalam promosi ini adalah website, fotografi dan video maka nantinya akan mendominasi visualisasi dalam media promosi Pasar Papringan. Berikut penjelasan beberapa komponen visualnya:

\section{a) Foto}

Menggunakan teknik fotografi makanan atau food photography dengan menggunakan kamera DSLR atau digital single lens reflex dan lensa $50 \mathrm{~mm}$ bukaan aperture yang besar sehingga tampak background lebih blur dan titik fokus menjadi sempit, sehingga hanya fokus pada makanan atau minuman, kebudayaan maupun kerajinannya.

\section{b) Video}

Menggunakan teknik zoom pada beberapa video shot kebun bambu, menggunakan teknik mengambil gambar dengan subjek tidak hanya direkam hanya makanan saja namun shot lain seperti mulai dari pintu masuk Pasar Papringan, lalu ada tugu 0 km, dan lainnya. Teknik pengambilan latar belakang dengan wide shot untuk memberikan petunjuk lokasi agar lebih spesifik, fokus pada hal-hal detail seperti pada penjual kerajinan dan penjual makanan minuman agar penyampaian pesan yang pas kepada audiens dan penekanan terhadap suatu subjek, menggunakan angle yang berbeda-beda yaitu dari samping kanan ke kiri, samping kiri ke kanan, dari atas ke bawah, dan dari bawah ke atas. 
Serat Rupa Journal of Design, July 2019, Vol.3, No.2: 93-111

E-ISSN: 2477-586X, ISSN: 2338-3348 | https://doi.org/10.28932/srjd.v3i2.1160 | Received: 07-01-2018, Accepted: 25-07-2019

Steven Arden, R.A. Dita Saraswati, Puspita Yuli Pradita

Perancangan Desain Grafis Media Promosi Website Pasar Papringan Bagi Keluarga Urban di Indonesia

\section{c) Ilustrasi}

Menggunakan gaya vektor yang sederhana untuk memudahkan audiens dalam memahami isi dan tujuan dari website tersebut yaitu memberikan informasi tentang Pasar Papringan.

\section{d) Layout}

Layout yang dibuat menggunakan prinsip Rule of Third, yaitu aturan praktis atau pedoman yang berlaku untuk proses penyusunan gambar visual seperti desain, film, lukisan, dan foto. Pedoman ini mengusulkan bahwa suatu gambar harus dibayangkan dibagi menjadi sembilan bagian yang sama oleh dua garis horizontal dengan jarak yang sama dan dua garis vertikal dengan jarak yang sama, dan elemen komposisi yang penting harus ditempatkan di sepanjang garis ini atau persimpangannya (Beaird, 2010), diperlihatkan pada gambar 5 .

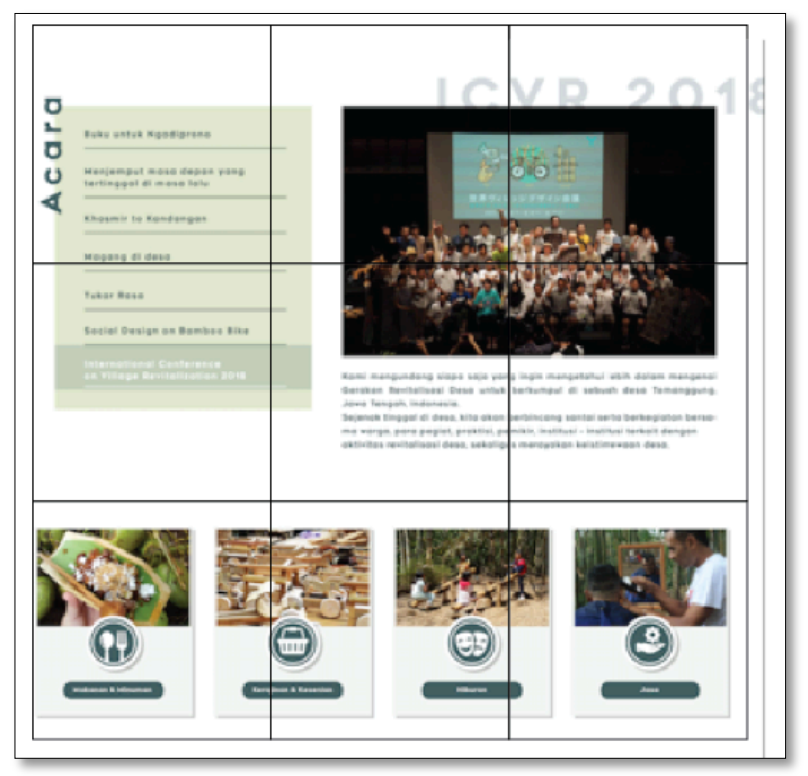

Gambar 5. Rule Of Third pada Lay Out Website

e) Tipografi

(Sumber: Data penulis, 2018)

Berikut jenis huruf yang digunakan pada website:

Renogare

ABCDEFGHIJKLMNOPQRSTUVWXYZ abcdefghjkImnopqrsturwXyz 1234567890

Gambar 6. Tipografi Font Renogare

(Sumber: Data penulis, 2018) 
Jenis huruf Renogare digunakan pada konten website dan media lainnya, serta setiap bagian website seperti untuk penjelasan makanan, minuman, kesenian, dan kerajinan di website Pasar Papringan kebanyakan menggunakan font ini. Jenis huruf ini memiliki karakter santai, dapat dibaca dengan mudah, modern dan sederhana agar audiens tidak cepat lelah dan bosan ketika membaca.

\section{Signature of the Andent

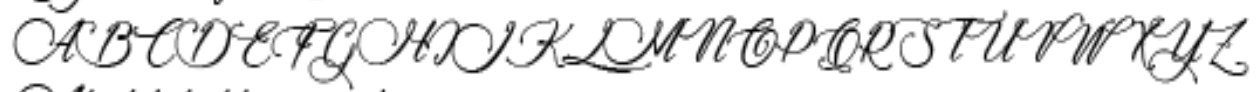 Abcdetahijelmnoparsturoxyy 1234567890}

Gambar 7. Tipografi Font Signature of the Andent (Sumber: Data penulis, 2018)

Jenis huruf Signature of The Andent memiliki karakter yang terlihat lebih tradisional sebagai aksen pada laman website.

\section{f) Warna}

Penggunaan warna dalam perancangan media promosi Pasar Papringan ini adalah hijau tua, hijau muda, putih, dan kuning. Pemilihan warna tersebut diambil dari warna alam. Gabungan warna ini bersifat kuat dan membangkitkan selera atau tertarik untuk mencari informasi tentang Pasar Papringan dan segera mengunjungi Pasar Papringan secara langsung. Warna hijau tua dan hijau muda melambangkan bambu dan kekayaan alam, warna putih melambangkan Pasar Papringan yang bersih, dalam artian bersih dari sampah yaitu sampah plastic. Selain itu warna putih melambangkan makanan khas Jawa Tengah yang identik dengan kelapa parut. Warna kuning melambangkan ciri khas kerajinan, mainan, keranjang yang banyak menggunakan bambu yang sudah kering berwarna kuning.

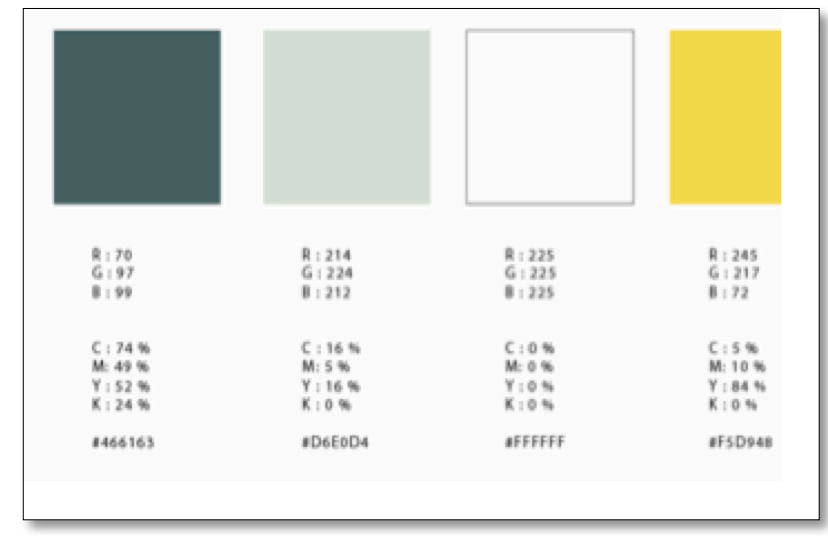

Gambar 8. Warna RGB, dan CMYK

(Sumber: Data penulis, 2018) 


\section{Hasil Karya}

Dibawah ini adalah hasil karya dari perancangan ini. Tampilan website terdiri dari beberapa pembagian laman dengan arahan wireframe sebagai berikut:

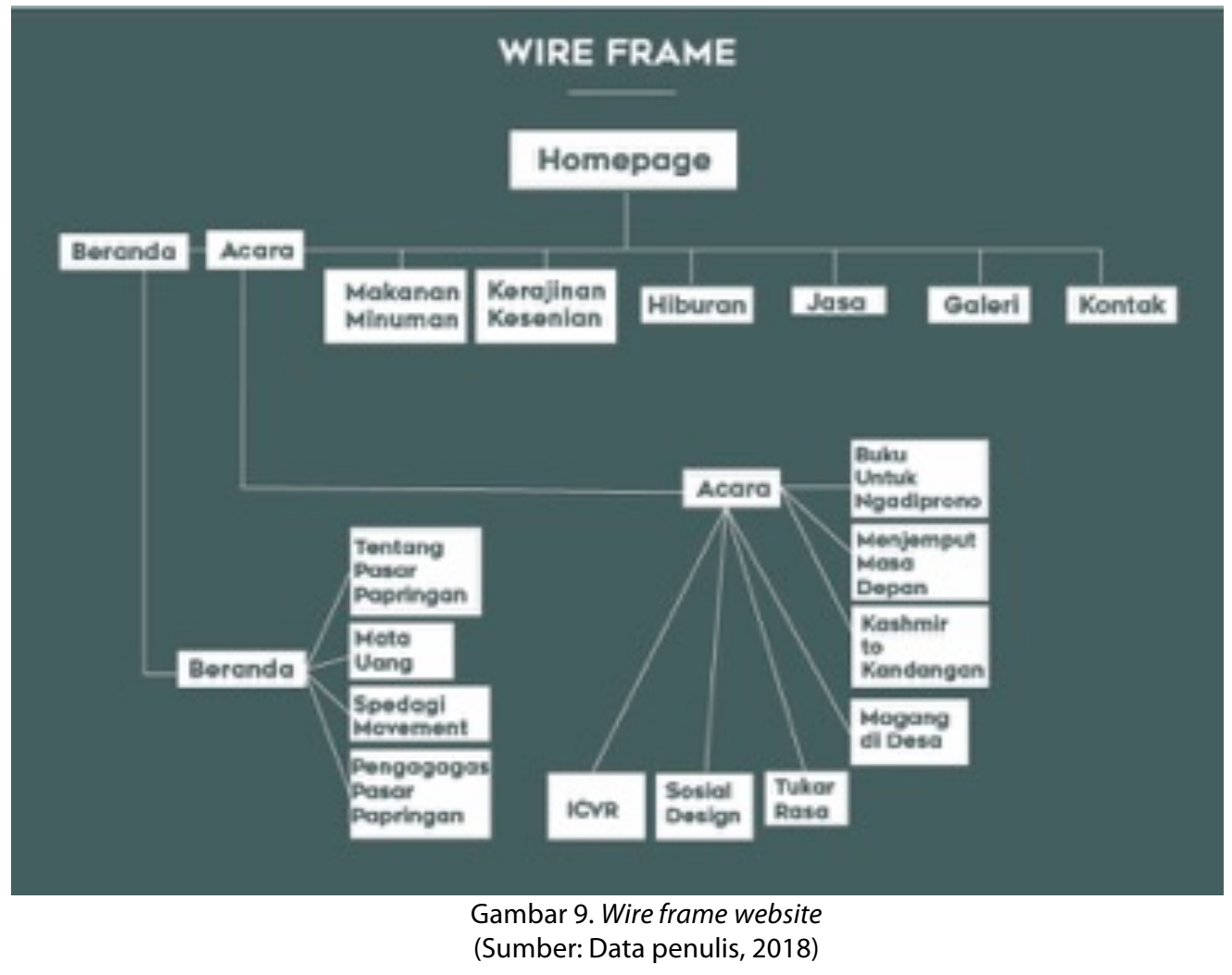

Dalam "Homepage" terdapat pilihan untuk menu "Beranda", "Acara", "Makanan Minuman", "Kerajinan Kesenian", "Hiburan", "Jasa”, "Galeri", dan "Kontak". Di dalam "Beranda" terdapat pilihan untuk mengetahui Tentang Pasar Papringan, Mata Uang, Spedagi Movement, dan Penggagas Pasar Papringan. Lalu dalam "Acara" ada pilihan untuk melihat acara apa saja yang ada di Pasar Papringan sebagai berikut: Buku untuk Ngadiprono, Menjemput Masa Depan, Kasmir to Kandangan, Magang di Desa, Tukar Rasa, Sosial Design, ICVR.

Selanjutnya di "Homepage" ada pilihan makanan minuman, kerajianan kesenian, hiburan, jasa, galeri, dan kontak. Di bawah ini merupakan hasil visualnya yang terdiri atas laman utama (homepage) (Gambar 10-13) dan juga laman kontennya. 
Serat Rupa Journal of Design, July 2019, Vol.3, No.2: 93-111

E-ISSN: 2477-586X, ISSN: 2338-3348 | https://doi.org/10.28932/srjd.v3i2.1160| Received: 07-01-2018, Accepted: 25-07-2019 Steven Arden, R.A. Dita Saraswati, Puspita Yuli Pradita

Perancangan Desain Grafis Media Promosi Website Pasar Papringan Bagi Keluarga Urban di Indonesia

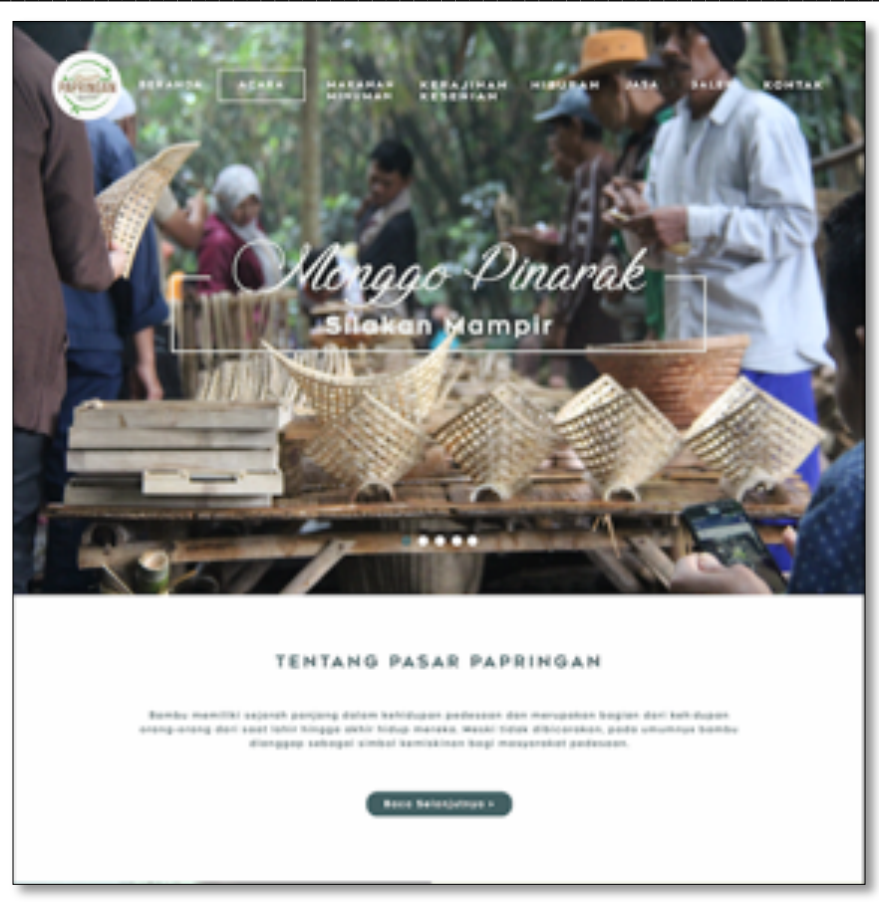

Gambar 10. Homepage website

(Sumber: Data penulis, 2018)
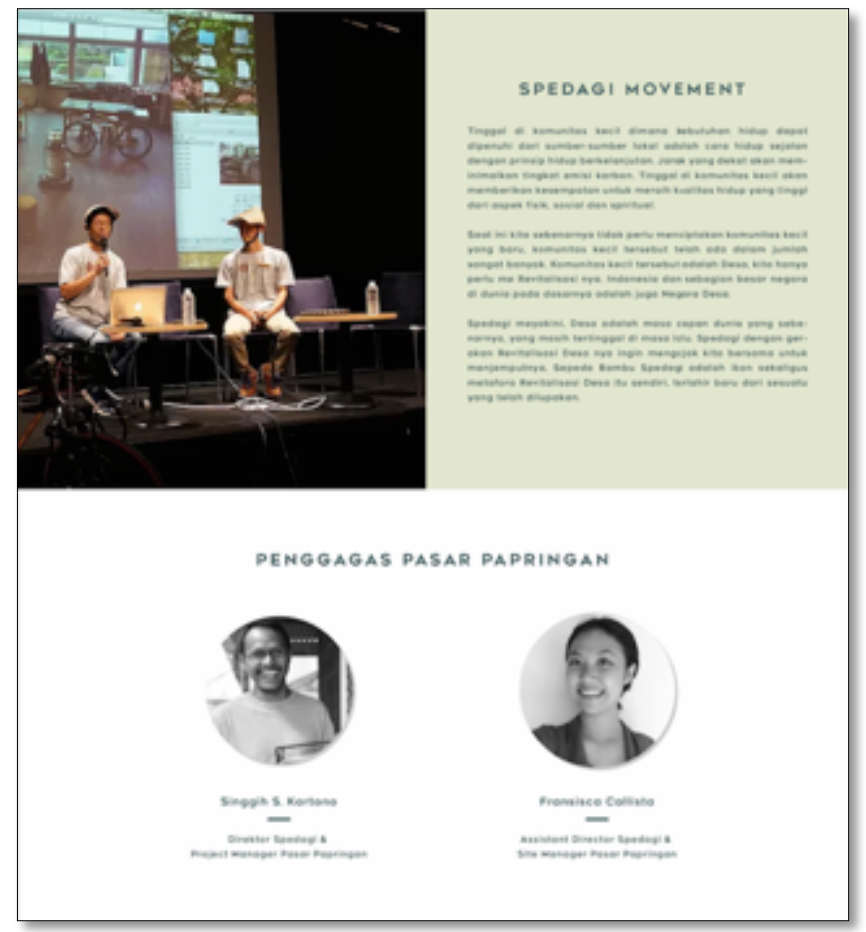

Gambar 11. Homepage website bagian Spedagi Movement dan penggagas (Sumber: Data penulis, 2018) 
Serat Rupa Journal of Design, July 2019, Vol.3, No.2: 93-111

E-ISSN: 2477-586X, ISSN: 2338-3348 | https://doi.org/10.28932/srjd.v3i2.1160 | Received: 07-01-2018, Accepted: 25-07-2019 Steven Arden, R.A. Dita Saraswati, Puspita Yuli Pradita

Perancangan Desain Grafis Media Promosi Website Pasar Papringan Bagi Keluarga Urban di Indonesia

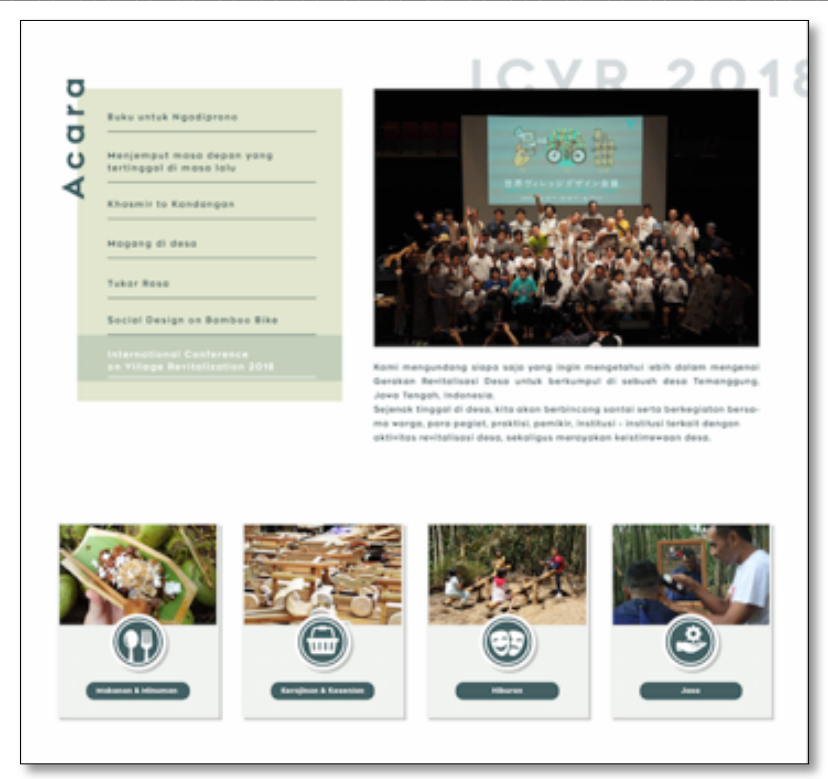

Gambar 12. Homepage website bagian acara dan apa saja yang ada di Pasar Papringan (Sumber: Data penulis, 2018)

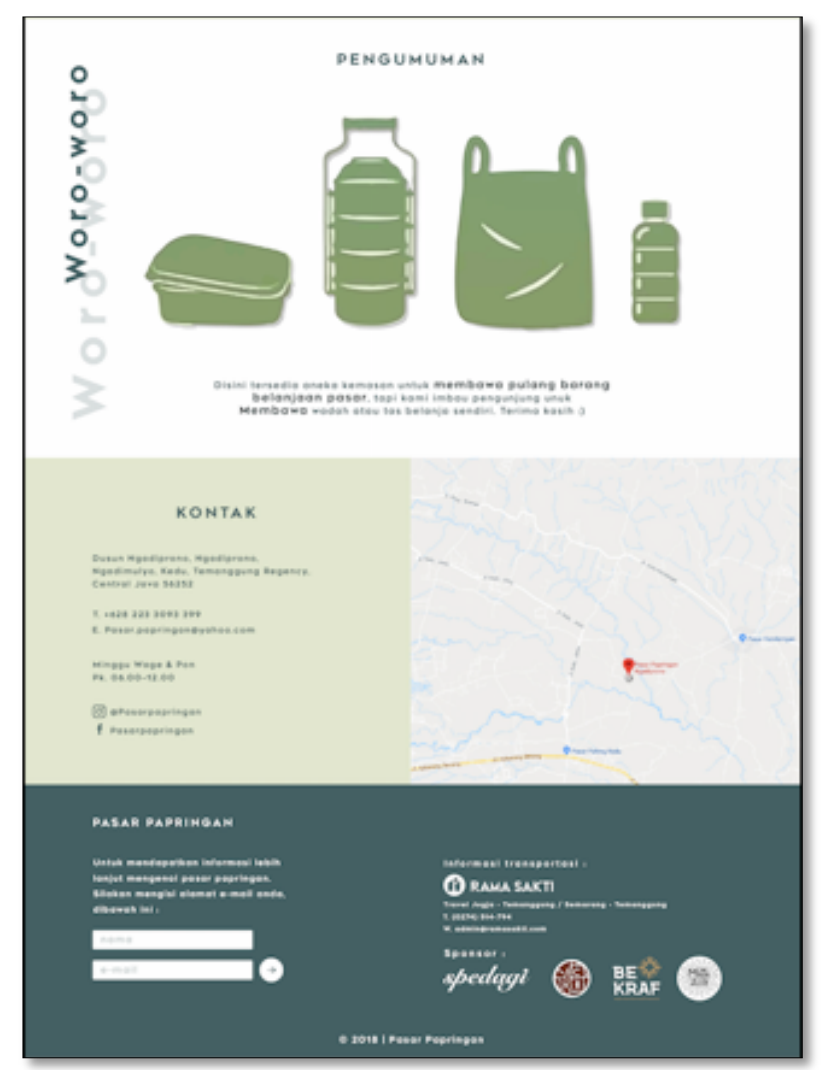

Gambar 13. Homepage website pengumuman, kontak atau letak lokasi informasi Pasar Papringan (Sumber: Data penulis, 2018) 
Serat Rupa Journal of Design, July 2019, Vol.3, No.2: 93-111

E-ISSN: 2477-586X, ISSN: 2338-3348 | https://doi.org/10.28932/srjd.v3i2.1160 | Received: 07-01-2018, Accepted: 25-07-2019 Steven Arden, R.A. Dita Saraswati, Puspita Yuli Pradita

Perancangan Desain Grafis Media Promosi Website Pasar Papringan Bagi Keluarga Urban di Indonesia

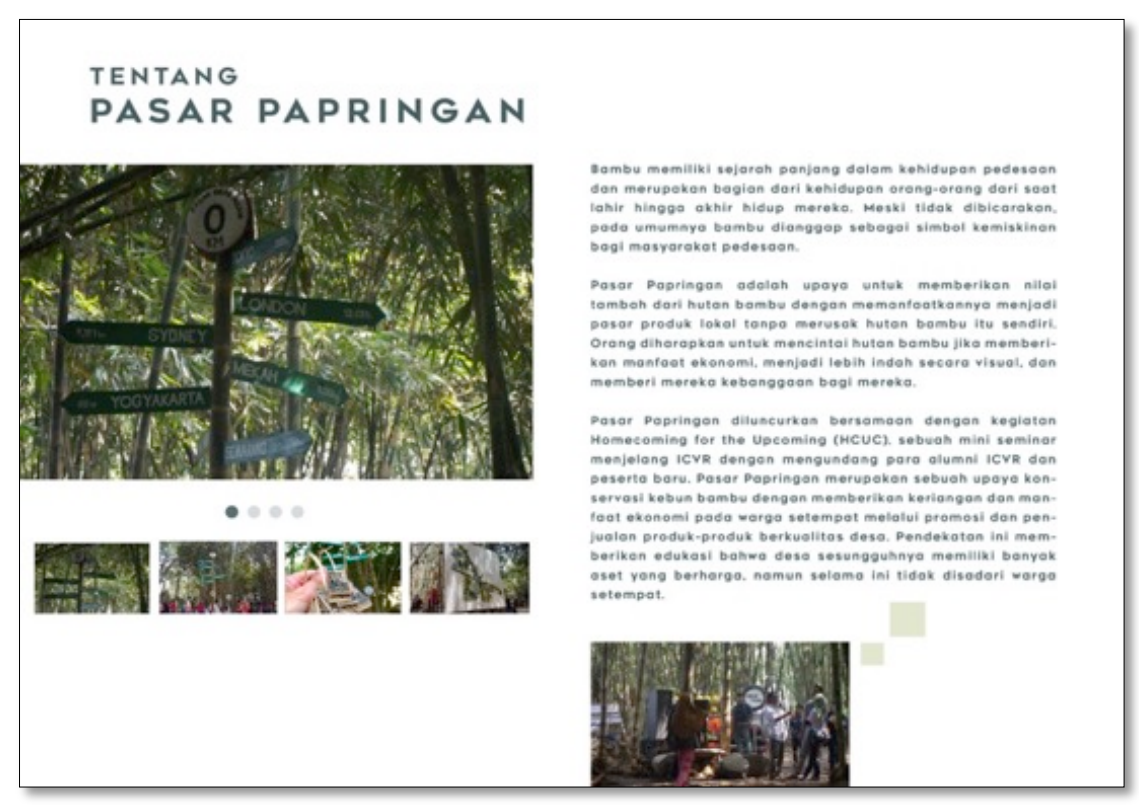

Gambar 14. Page konten tentang Pasar Papringan (Sumber: Data penulis, 2018)

Gambar 14 adalah halaman tentang Pasar Papringan, apabila pengguna memilih atau klik "Beranda" pilih "Pasar Papringan", maka halaman ini akan terbuka dan pengguna langsung ditujukan ke Tentang Pasar Papringan. Pada halaman ini menggunakan satu blok desain dengan sistem klik untuk ke home, blok ini berisi foto dan juga penjelasan Pasar Papringan.

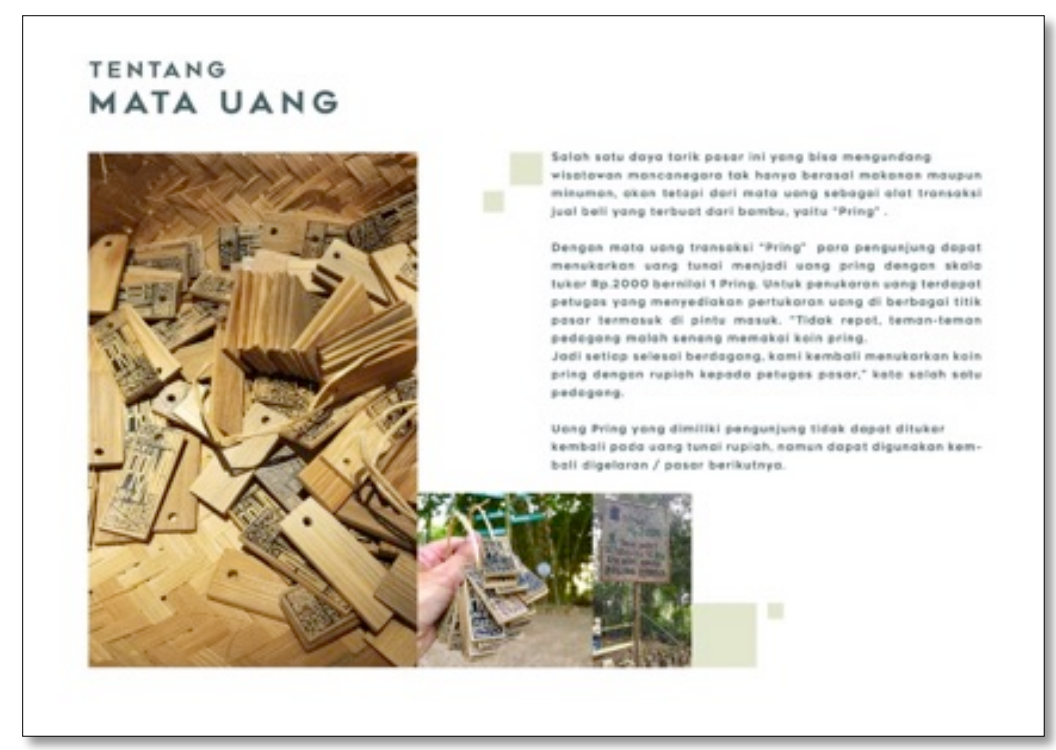

Gambar 15. Page konten tentang mata uang Pring (Sumber: Data penulis, 2018)

Gambar 15 merupakan halaman informasi tentang mata uang. Apabila diklik "beranda" pilih "mata uang" maka akan masuk ke halaman ini atau halaman tentang mata uang dan dijelaskan tentang mata uang Pasar Papringan yaitu koin Pring. 
Serat Rupa Journal of Design, July 2019, Vol.3, No.2: 93-111

E-ISSN: 2477-586X, ISSN: 2338-3348 | https://doi.org/10.28932/srjd.v3i2.1160| Received: 07-01-2018, Accepted: 25-07-2019

Steven Arden, R.A. Dita Saraswati, Puspita Yuli Pradita

Perancangan Desain Grafis Media Promosi Website Pasar Papringan Bagi Keluarga Urban di Indonesia

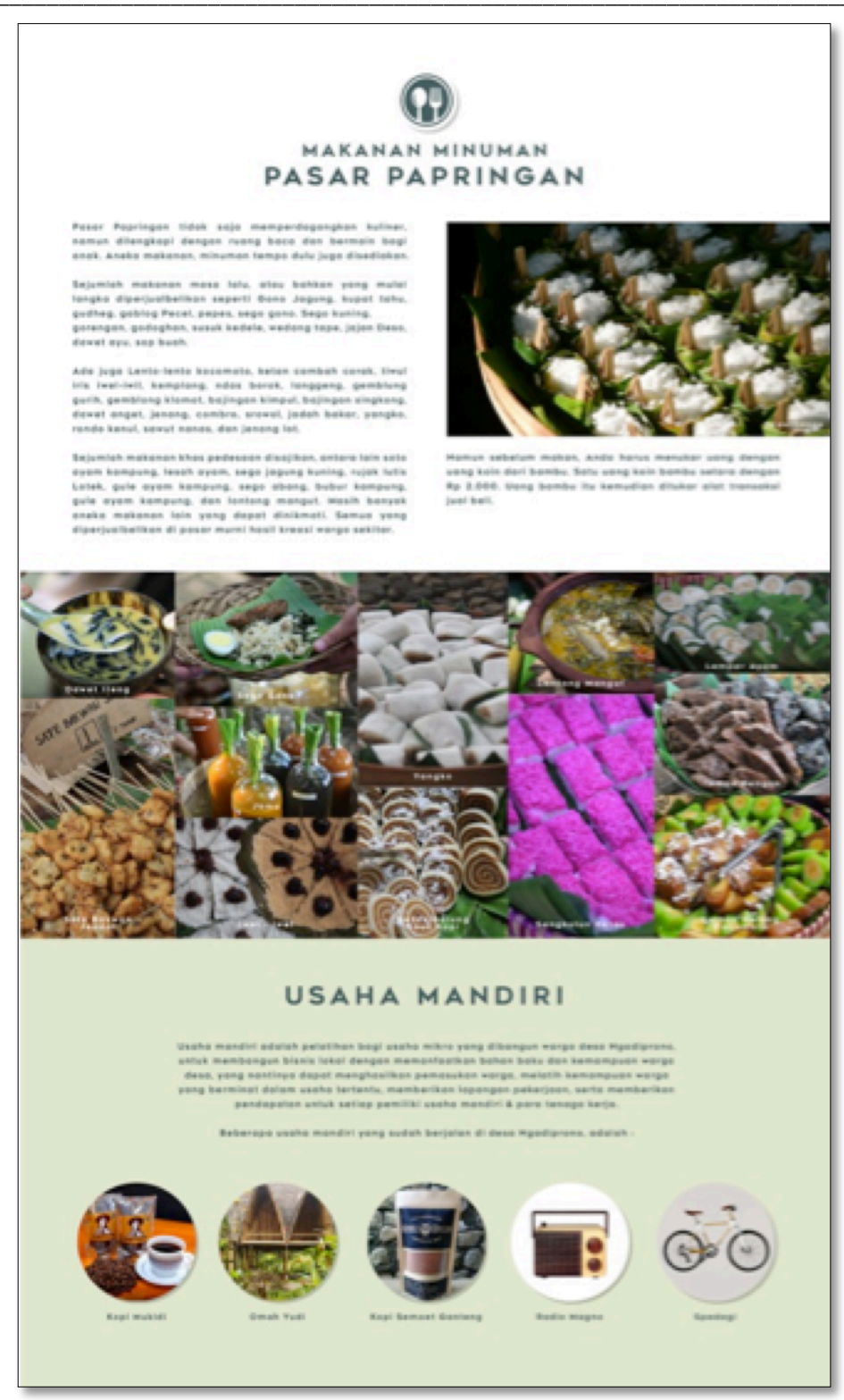

Gambar 16. Page konten tentang makanan-minuman Pasar Papringan (Sumber: Data penulis, 2018)

Gambar 16 adalah halaman yang berisi informasi makanan dan minuman yang ada di Pasar Papringan. Layout desain masih menggunakan satu blok, menampilkan foto dan juga nama makanan minuman yang ada, tak hanya itu di halaman ini juga terdapat penjelasan dan juga foto produk atau jasa tentang usaha mandiri yang berada di sana. 
Serat Rupa Journal of Design, July 2019, Vol.3, No.2: 93-111

E-ISSN: 2477-586X, ISSN: 2338-3348 | https://doi.org/10.28932/srjd.v3i2.1160| Received: 07-01-2018, Accepted: 25-07-2019 Steven Arden, R.A. Dita Saraswati, Puspita Yuli Pradita

Perancangan Desain Grafis Media Promosi Website Pasar Papringan Bagi Keluarga Urban di Indonesia

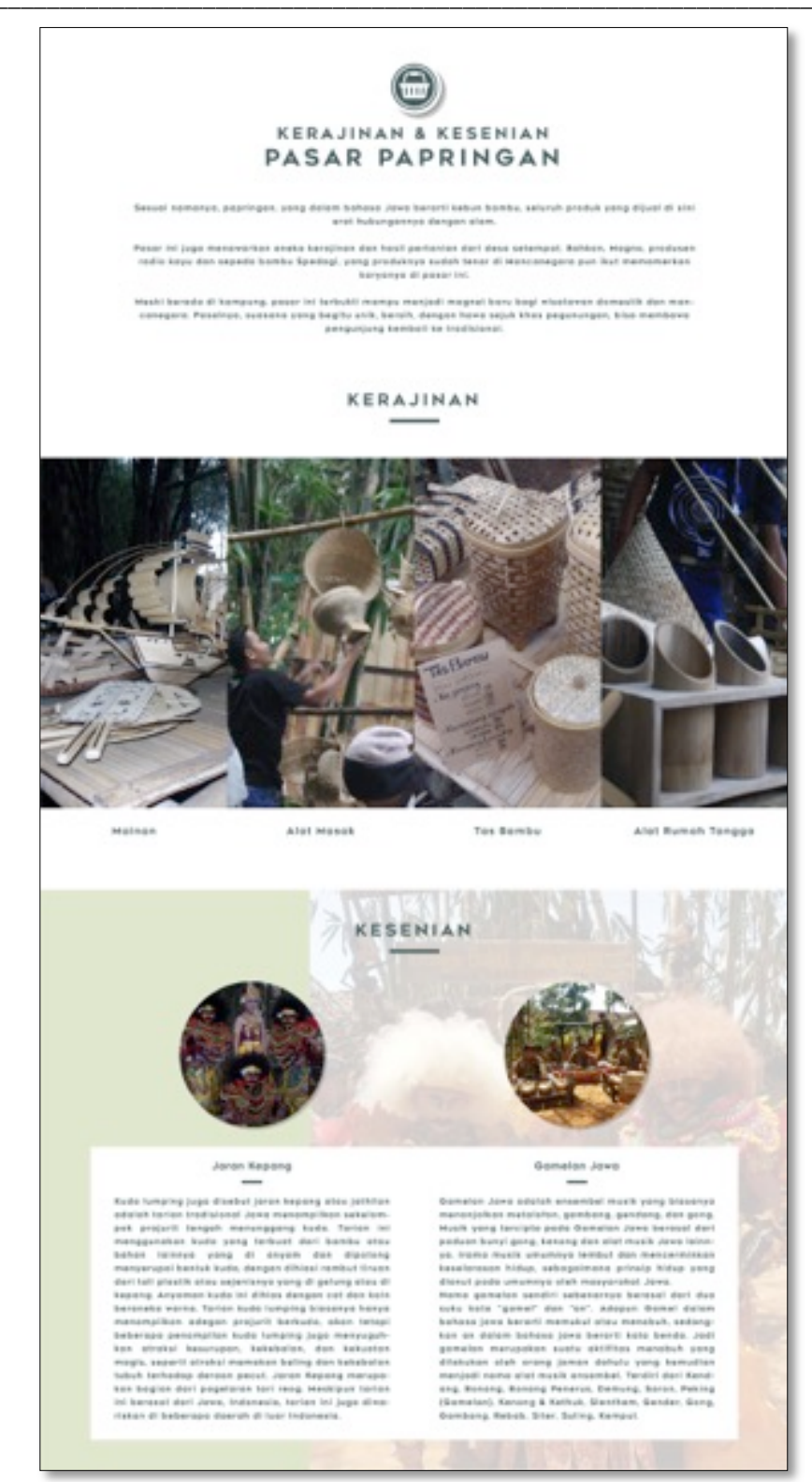

Gambar 17. Page konten tentang kerajinan kesenian Pasar Papringan (Sumber: Data penulis, 2018)

Gambar 17 adalah halaman yang berisi informasi mengenai kerajinan yang dijual di Pasar Papringan dan kesenian yang ada di Pasar Papringan. Pada halaman ini menggunakan satu blok desain dan masih memakai layout desain yang berbeda, di dalam blok ini menampilkan foto produk dan kerajinan. 
Serat Rupa Journal of Design, July 2019, Vol.3, No.2: 93-111

E-ISSN: 2477-586X, ISSN: 2338-3348 | https://doi.org/10.28932/srjd.v3i2.1160| Received: 07-01-2018, Accepted: 25-07-2019

Steven Arden, R.A. Dita Saraswati, Puspita Yuli Pradita

Perancangan Desain Grafis Media Promosi Website Pasar Papringan Bagi Keluarga Urban di Indonesia

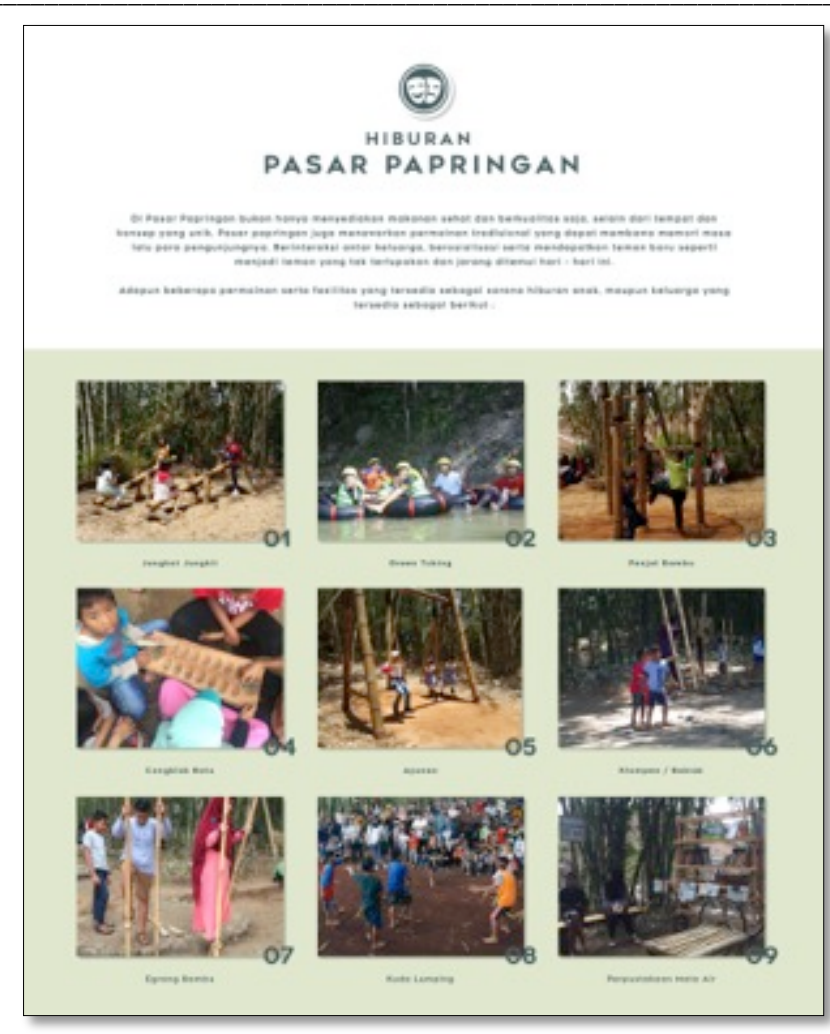

Gambar 18. Page konten tentang Hiburan Pasar Papringan

(Sumber: Data penulis, 2018)

Gambar 18 adalah halaman yang berisi hiburan untuk mengetahui hiburan permainan tradisional untuk anak-anak maupun untuk dewasa. Permainan yang ada di Pasar Papringan merupakan permainan tradisional yang makin sulit ditemui di zaman sekarang. Pada halaman ini digunakan satu blok desain dan dapat kembali ke home. Isi dalam halaman ini memberi informasi tentang foto hiburan permainan Pasar Papringan.

\section{PENUTUP}

Melalui proses pembuatan media promosi ini diharapkan Pasar Papringan dapat lebih dikenali oleh warga di kota-kota besar di Indonesia. Sekaligus dapat menjadi contoh untuk desa-desa lain untuk berkarya sekaligus menjaga dan merawat lingkungannya, hidup sehat dengan mengkonsumsi makanan sehat dan tradisional yang mulai sulit ditemukan di tempat lain, melestarikan budaya dan kerajinan, memberikan pekerjaan bagi profesiprofesi yang sekarang mulai sulit di cari. Warga di kota-kota besar di Indonesia khususnya dapat tertarik mengunjungi Pasar Papringan lewat media promosi yang ada. 
Serat Rupa Journal of Design, July 2019, Vol.3, No.2: 93-111

E-ISSN: 2477-586X, ISSN: 2338-3348 | https://doi.org/10.28932/srjd.v3i2.1160| Received: 07-01-2018, Accepted: 25-07-2019

Steven Arden, R.A. Dita Saraswati, Puspita Yuli Pradita

Perancangan Desain Grafis Media Promosi Website Pasar Papringan Bagi Keluarga Urban di Indonesia

\section{DAFTAR PUSTAKA}

Arwiedya, Mochamad Ridzky. 2011. Analisis Pengaruh Harga, Jenis Media, Promosi Resiko

Kinerja, dan Keragaman Produk Terhadap Keputusan Pembelian Via Internet Pada

Toko Online (Studi Kasus Pada Konsumen Toko Fashion Online yang bertindak

sebagai Reseller yang ada di Indonesia. Jurnal Ekonomi UMS.

Beaird, Jason. (2010). The Principles of Beautiful Web Design. Canada: Sitepoint publisher.

Kasali, Rhenald. (1992). Manajemen Periklanan Konsep dan aplikasinya di Indonesia.

Jakarta: Pustaka Utama Grafiti.

Maulana, E. Amalia (2008). The End of The Line: Mengakhiri istilah ATL dan BTL. Personal

Website: http://amaliamaulana.com/popular-article/the-end-of-the-line-

mengakhiri-penggunaan-istilah-atl-vs-btl/ [28 April 2018]

Russel, J. Thomas \& W. Ronald Lane (1992). Tata Cara Periklanan Kleppner, Buku Pertama. Jakarta: PT Elex Media Komputindo.

Simamora, Bilson. (2003). Memenangkan Pasar dengan Pemasaran Efektif \&. Profitabel, Gramedia Pustaka Utama, Jakarta.

Suyanto, Asep Herman. 2008. Step by Step Web Design Theory and Practice Edisi II. Yogyakarta: Andi Publisher. 